\title{
AS RAÍZES DA CORRUPÇÃO BRASILEIRA
}

\section{THE ROOTS OF BRAZILIAN CORRUPTION}

Reis Friede*

Resumo: Diante da flagrante e inconteste realidade brasileira, a exemplo de tantas outras nações subdesenvolvidas ou em permanente via de desenvolvimento, é amplamente aceita a tese segundo a qual o agigantamento do Estado encontra-se intimamente associado à corrupção, tanto no sentido de sua indução caracterizadora quanto de sua manutenção reprodutiva. Esta problemática possui inegáveis precedentes históricos, que serão abordados no texto de forma objetiva, como também se apresentará outra possibilidade de explicação para a origem da corrupção no Brasil, que vai além da que atribui essa mazela ao fato dos degredados serem enviados para cá no período colonial.

Palavras-chave: Corrupção. Degredados. Estado Corrupto.

Abstract: Faced with the flagrant and uncontested Brazilian reality, like so many other underdeveloped nations or in a permanent way of development, the thesis is widely accepted that the enlargement of the State is closely associated with corruption, both in the sense of its characterizing induction and reproductive maintenance. This problem has undeniable historical precedents, which will be approached in the text in an objective way, as well as another possibility of explanation for the origin of corruption in Brazil, which goes beyond what is attributed to the fact that the degredados are sent here in the period colonial.

Keywords: Corruption. Degredados. Corrupted State.

\footnotetext{
* Desembargador Federal, Presidente do Tribunal Regional Federal da 2a Região (biênio 2019/21), Mestre e Doutor em Direito e Professor Adjunto da Universidade Federal do Estado do Rio de Janeiro (UNIRIO). Site: https://reisfriede.wordpress.com/. E-mail: reisfriede@hotmail.com
} 
"Sabei, moços, que há inferno, e não fica longe; é aqui."

(RUBEM BRAGA)

\section{INTRODUÇÃO}

É consagrada a tese segundo a qual o agigantamento do Estado encontra-se intimamente associado à corrupção, tanto no sentido de sua indução caracterizadora quanto de sua manutenção reprodutiva. Destarte, esta é a flagrante e inconteste realidade brasileira, a exemplo de tantas outras nações subdesenvolvidas ou, em uma terminologia artificialmente construída, e em absoluta desconexão com a realidade, em permanente via de desenvolvimento. Esta problemática possui inegáveis precedentes históricos, cujo início deu-se já em 1500, quando Pedro Álvares Cabral descobriu o Brasil.

No final do século XV, Portugal empenhava-se em povoar tanto o Brasil como suas demais colônias. Neste cenário, as penas de degredo aumentaram exponencialmente: qualquer pequeno delito era motivo para o exílio, podendo ser este um dos fatores determinantes na criação de uma mentalidade que favoreceria a corrupção no Brasil. Trata-se, no entanto, de um raciocínio simplista. Afinal, como se sabe, a maioria dos degredados eram condenados por delitos dotados de baixo potencial ofensivo, como vadiagem, adultério, "bruxaria" e por aí vai. Havia ainda uma boa parcela de presos políticos e religiosos.

Apenas para ilustrar, sabe-se que D. João, ao desembarcar, em 1808, no Rio de Janeiro, recebeu de presente de um traficante de escravos o terreno da aprazível Quinta da Boa Vista. Em reconhecimento ao "agrado" recebido, a Família Real Portuguesa assegurou a Elias Antônio Lopes, o "despretensioso" doador, o status de amigo do Rei.

O que se percebe, portanto, é que a troca de favores entre senhores de engenho, fazendeiros e traficantes de escravos já era comum desde o Brasil Colônia, caracterizando, por assim dizer, o famoso "toma lá dá cá", frase que se tornou uma das marcas registradas do País. Como se vê, os negócios públicos e privados, desde aquela época, já se enleavam, eis que os títulos de nobreza eram concedidos (direta e objetivamente) em troca de dinheiro. 
De fato, um País que, por herança de sua formação, constitui-se em um Estado altamente centralizado, burocratizado e clientelista, bem como fortemente distante dos princípios da ética e da moral, acaba por funcionar como um autêntico indutor da corrupção.

As razões de Portugal (e também Espanha) terem se constituído, ao longo da história, em Estados altamente centralizadores e, consequentemente, burocratizantes, deve-se, em grande medida, às invasões muçulmanas que atingiram a Península Ibérica, poupando, outrossim, a porção central e superior do continente europeu.

Por conseguinte, esta acabou sendo a principal e a mais profunda herança lusitana que a sociedade brasileira, desde o seu descobrimento em 1500, recebeu e quase que automaticamente incorporou ao cotidiano, inclusive aperfeiçoando muitas de suas práticas concentradoras de poder, tornando-se, em muitos aspectos, uma coletividade culturalmente ainda mais burocratizante e corrupta em relação à sua matriz e irradiadora ideológica. A título de exemplo, cabe registrar que, em oito anos, D. João VI distribuiu mais títulos de nobreza do que em 700 anos de monarquia portuguesa. Segundo Romulo F. Federici (2015, p.85):

Poucos séculos após a chamada "Queda do Império Romano", cujo ano de 476 d.C. (deposição do último imperador) é apenas um marco de um processo que já vinha de muito, os árabes ou mouros (como os romanos os chamavam pela pele mais morena) se uniram culturalmente e religiosamente sob o Islã, iniciando sua expansão para a África e conquistando a Península Ibérica. Por pouco não conquistaram toda a atual Europa, seja a partir da Ibéria, a oeste, ou pelo leste no território hoje da Hungria e Romênia. Começavam vários séculos de lutas por disputa de terras por parte dos reinos cristãos, com cruzadas a leste e a oeste. O lento mas firme sucesso destas últimas resultou na consolidação de Estados de forte poder central como Portugal e Espanha, que nos séculos XV e XVI lançariam esse espírito de cruzada para além-mar, navegando e conquistando outros continentes para os europeus (e exportando, em última análise, esta doutrina centralizadora e indutora da corrupção).

Interessante consignar que 0 fato de o Rei e seus Ministros usarem o dinheiro público para fins particulares não era entendido como corrupção pela maioria da população. Pessoas ligadas ao Rei e seus parentes eram agraciados com 
empregos públicos, sendo o nepotismo uma prática deveras comum e, particularmente à época, legal (PAINS, 2015, p. 25).

Decerto que tal característica, embora não seja exclusividade nacional, restou devidamente enraizada no Estado brasileiro. A propósito, analisando-se a presente questão na atualidade, observa-se que a Petrobras - nossa principal empresa paraestatal e que foi um dos principais alvos da Operação Lava-Jato - já tinha enfrentado outras investigações conduzidas por Comissões Parlamentares de Inquérito (CPI) instaladas no Congresso Nacional. Dirigentes da aludida Estatal, criada em 1953 por Getúlio Vargas, vêm sendo convocados para esclarecimentos desde os governos de Juscelino Kubitschek e João Goulart. Após o período relativo às administrações militares - em que inexistem registros de desvios de recursos públicos na estatal que sejam dignos de menção -, a referida empresa petrolífera protagonizou escândalos nos governos Sarney e Collor.

Se é fato que os índices de corrupção durante o Regime Militar (1964-1985) foram um dos mais baixos da história do Brasil, certamente é também cediço reconhecer que existiram alguns escândalos de corrupção durante esse período governamental. A diferença fundamental, todavia, encontra-se na intensidade quanto à exteriorização do fenômeno e, também, em sua natureza "varejista", em contraposição à concepção "atacadista" que prevalece nos dias atuais, repetindo, em maior escala e sofisticação, a ideia originária (de compra de apoio político e de financiamento de campanhas eleitorais) concebida no período getuliano. Os escândalos da época seriam hoje considerados menores, em função da dimensão (aspecto vertical) e da própria extensão (aspecto horizontal) da corrupção verificada nos dias atuais.

Como exemplos de algumas isoladas iniciativas destinadas ao combate à corrupção, convém lembrar que o governo João Figueiredo (1979-1985) criou o Ministério Extraordinário da Desburocratização, pasta titularizada pelo Ministro Hélio Beltrão, cujo objetivo central era reduzir a burocracia e, consequentemente, diminuir os índices de corrupção. Da mesma forma, durante a existência do aludido Ministério foram criados os Juizados de Pequenas Causas e o Estatuto da Microempresa. É importante registrar que a excessiva regulamentação estatal, - além de funcionar 
como elemento primordial para a construção originária das bases para a instalação da corrupção em uma nação (em todas as suas dimensões) -, opera, igualmente, na qualidade de autêntico retroalimentador de tal fenômeno.

Uma das dificuldades da construção da cidadania (e da democracia) no Brasil é o "peso do passado", sobretudo em razão do período colonial (1500-1822), quando os portugueses tinham construído um enorme País [...], mas deixado uma população analfabeta, uma sociedade escravocrata, uma economia monocultora e latifundiária e um Estado Absolutista. (CREMONESE, 2007, p. 62).

No entanto, as raízes culturais profundas, fruto, em grande medida, do modelo de colonização concebido por Portugal, explicam, apenas em parte, o retrato sombrio do Estado que, passo a passo, foi construído, consciente e inconscientemente, para se servir do cidadão, ao invés de servir ao cidadão.

\section{A NECESSÁRIA RUPTURA DE UM INFELIZ PARADIGMA NACIONAL}

Lamentavelmente, o Estado que se deseja "passar a limpo" necessita muito mais do que uma simples alteração das históricas e escusas relações entre o público e o privado, ainda que tal iniciativa seja reconhecidamente fundamental para se promover a mudança que tanto se almeja. Destarte, somente uma transformação de grande monta na própria concepção estrutural do Estado - e, particularmente, na maneira como a sociedade o vê e o concebe - será capaz de alterar radicalmente a atual postura político-estatal (e, ainda assim, gradativamente, ao longo de gerações), forjando as mesmas condições que permitiram que, historicamente, os Estados Unidos e os principais países europeus, bem como o Japão, ostentassem as respectivas qualidades de verdadeiras nações desenvolvidas.

Não é verdadeira a afirmação corrente de que a corrupção está (necessariamente) associada ao Estado autoritário. Mas é fato que muitos Estados autoritários, percebendo claramente os grandes males da corrupção, particularmente como obstáculos intransponíveis para um sustentado processo de crescimento econômico e desenvolvimento social, passaram a combater com grande eficiência o mal em questão. 
Mas, se por um lado é possível que um Estado autocrático possa combater com eficiência a corrupção, é também correto afirmar que não existe nenhum país verdadeiramente democrático que não tenha conseguido vencer a corrupção para auferir esta qualidade.

Destarte, todos os países que se reputam democráticos, mas que continuam a experimentar elevadas taxas de corrupção, retratam, na essência, apenas uma pseudodemocracia, ou, como desejam alguns autores, democracias formais ou de continente, desprovidas, portanto, de conteúdo e substância verdadeiramente democráticas.

Curioso observar que países que, de alguma forma, almejaram se desenvolver social e economicamente, bem como ampliar sua influência e respeito internacional, engajaram-se com vigor na luta contra a corrupção, reconhecendo ser este o principal obstáculo ao crescimento econômico. Ainda que as autoridades acusadas de tal conduta geralmente se defendam afirmando serem perseguidos políticos (o que até pode ser verdadeiro, em parte), é também interessante notar que este é o discurso "padrão" frequentemente decorado e repetido por aqueles que se veem envolvidos em escândalos dessa natureza.

A propósito do tema, cumpre consignar que o Brasil ocupa a 96a posição no Índice de Percepção da Corrupção/2018, que analisa o tema corrupção - palavra que provém do latim corruptione, que agrega a ideia de corromper, e que pode significar decomposição, putrefação, desmoralização, suborno - no setor público em 180 países e territórios, segundo pesquisa realizada e publicada pela Agência Brasil (SOUZA, 2018).

No caso do Brasil, em particular, a corrupção - de forma muito bem diferenciada e aguda - tem se enraizado cada vez mais em todas as camadas do Estado e da sociedade, e continua fazendo vítimas e privando grande parte da população das necessidades mais básicas, que vão desde uma alimentação mínima a mortes em filas de hospitais, enquanto outro segmento se enriquece a custa do bem público, aumentando cada vez mais o nível de desigualdade e exclusão social, gerando, assim, uma absoluta falta de confiança nas instituições, inclusive na própria Justiça. 
[...] Os últimos trinta anos da propalada era democrática vêm sendo marcados por incertezas e desgovernos com vários escândalos; Anões do Orçamento, dos Correios, Mensalão e, recentemente, o Petrolão.

Mais uma vez o povo brasileiro se vê enganado pelas promessas políticas, vivendo uma aparelhada democracia de conveniência, em que todos os direitos são garantidos à classe dirigente numa verdadeira ditadura oligárquica de dois Partidos majoritários, que chegam a reciclar seus correligionários derrotados nos Estados, aquinhoando-os com cargos no Governo, coadjuvados que são por Partidos satélites, de aluguel, todos ávidos por nacos do Poder, assistidos por uma Oposição contemplativa, sufocada e inoperante. Democracia defendida por uma Imprensa soberana, formadora de opinião, que chama de democracia, tão somente a sua liberdade de expressão e o voto direto dos cidadãos que, em sua maior parte, não sabem o valor do voto e muito menos o que é democracia, pois só têm deveres, desconhecendo os seus direitos. Assim, vivemos mais um "faz de conta". [...] (MONTEIRO, 2017, p. 31).

Um País que há muito é dominado por uma elite econômica, gasta muitíssimo mal os escassos recursos públicos e concebe políticas públicas quase sempre destinadas à concentração de renda e à obtenção de capital para abastecer financeiramente quem está no poder, permite-nos concluir que a corrupção não é apenas uma forma ilícita e imoral de enriquecimento. Ela serve também como uma espécie de estrutura para garantir estabilidade e sustentação - independentemente do partido político - a um esquema de perpetuação de organizações criminosas vinculadas ao Estado.

No Brasil, a corrupção, por si só, não derruba governos. É necessária a conjugação de dois fatores concomitantes para que tal aconteça: a corrupção e a ausência de apoio político congressional. A corrupção no governo Fernando Collor somente foi derradeira para o processo de impeachment quando o Presidente perdeu o apoio político-legislativo. O mesmo sucedeu, em uma autêntica "repetição histórica", com o governo Dilma Rousseff. Por outro lado, mesmo com todos os escândalos de corrupção ocorridos nos governos Juscelino Kubitschek, Luiz Inácio Lula da Silva e de tantos outros, tal fato, isoladamente considerado, não foi bastante poderoso para o afastamento de seus respectivos mandatários, uma vez que todos contavam com amplo apoio congressional, independentemente da forma como o obtiveram. 
Tal cenário obsta o efetivo desenvolvimento econômico, diminui - em termos reais ainda que não nominais - a arrecadação de tributos, bem como contribui para a péssima qualidade dos serviços prestados.

\section{3 "DIFICULDADE" GERA "FACILIDADE": A LÓGICA ECONÔMICA DA CORRUPÇÃO}

Efetivamente, não é por coincidência que grandes escândalos de natureza econômica e política têm no seu epicentro autarquias, empresas públicas e sociedades de economia mista. A multiplicação desenfreada de casos de corrupção pode ser atribuída, em grande parte, à desmedida e indevida intromissão do Estado na vida do cidadão e na economia.

Uma "engrenagem travada" é observada, por exemplo, no serviço de emissão de passaporte. Afinal, para se obter tal documento de viagem, exige-se do cidadão uma série de documentos (documento de identidade, certidão de nascimento ou casamento, título de eleitor e último comprovante de votação, documento que comprove quitação com o serviço militar, Cadastro de Pessoas Físicas - CPF, passaporte anterior, se existente - todos em original e cópia), muitos dos quais absolutamente redundantes, não obstante a existência de legislação que determina que as cópias autenticadas valham como originais.

Em suma, não basta o denominado RG (registro geral) emitido pelo Estado, no qual já constam todos os dados da certidão de nascimento, além do CPF. Desconfiado de si mesmo, uma vez que considera insuficiente um documento por ele expedido, o ente estatal exige redundantemente que se lhe apresente também a certidão de nascimento (pré-requisito legal para a expedição do RG). Tal Estado efetivamente complica a vida do cidadão.

Ademais, como se não bastasse o alto custo do documento para o cidadão (cerca de $R \$ 257,25$, em valores de 2018), o seu prazo de validade (atualmente ampliado para 10 anos, após as mais diversas críticas dos cidadãos), é bem inferior a muitos países, fazendo com que haja uma arrecadação permanente de taxas para a realização do serviço, sem que se observe, no entanto, a correspondente melhoria do sistema. 
Com isso não se pretende afirmar que a denominada administração direta seja imune ao mal da corrupção. É óbvio que tal carcinoma encontra-se alojado em vários órgãos do corpo estatal, dando azo a uma espécie de metástase. O que se quer dizer é tão somente que as chamadas paraestatais, por realizarem diversas operações comerciais e financeiras, oferecem múltiplas oportunidades de fraudes e financiamentos escusos - tal como o famoso e inescrupuloso "caixa dois" - a projetos políticos e eleitorais de objetivo duvidoso, mantendo, ainda, o alto padrão de vida da classe política, independentemente do partido.

A corrupção no Brasil também se apresenta de forma transideológica, na exata medida em que não distingue as clássicas (e tradicionais) concepções políticas de direita ou de esquerda. Exemplos dessa assertiva podem ser constatados através do fato de que tanto a direita (encarnada, outrora, por Getúlio Vargas e Juscelino Kubitschek) quanto representantes da esquerda (como João Goulart, dentre outros) tiveram envolvimento com a corrupção (de forma "institucionalizada") em seus respectivos governos.

Por efeito, pode-se afirmar que nos Estados em que se observa uma presença estatal massiva - quer da direita intervencionista, quer da esquerda participativa - a corrupção se apresenta em sua completa magnitude. Em contraste, é exatamente na concepção de Estado Liberal - e da sua correspondente e verdadeira acepção democrática de regime político -, em que a corrupção ou simplesmente inexiste ou se apresenta em sua menor gradação.

A corrupção, que hoje mantém a sociedade brasileira atônita, perplexa e rendida, é a mais grave e preocupante forma de violência praticada pelo Estado. De certo modo, e sem qualquer exagero, é lícito asseverar que o fenômeno em questão mata mais do que os fuzis que estão nas mãos dos narcotraficantes que aterrorizam as cidades brasileiras. Ademais, a corrupção guarda relação direta com as mais flagrantes violações aos direitos humanos. Basta analisar, por exemplo, o cruel e caótico sistema prisional brasileiro, cenário dos recentes massacres que aconteceram nos presídios do País, que mais se assemelham, segundo afirmação tornada pública pelo então Ministro da Justiça, José Eduardo Cardozo, às masmorras medievais, nos quais impera a absoluta e recorrente degradação da dignidade humana, e cuja 
verdadeira "administração" não se encontra na estrutura do Estado, mas nas mãos de organizações criminosas, tais como o Primeiro Comando da Capital (PCC) e o Comando Vermelho (CV).

O economista americano Robert Klitgaard, em entrevista à Claudia Andrade (2015), alerta que um crescimento rápido em um ambiente de elevada corrupção até é possível, a exemplo do que aconteceu na China, sendo certo que o combate à corrupção pode, até mesmo, ensejar, pontualmente, uma queda no desempenho da economia. Entretanto, esta situação rapidamente será remediada, e os benefícios serão enormes, na medida em que os frutos do crescimento serão igualmente repartidos a todos. Prossegue Klitgaard alertando que, depois de décadas de crescimento acelerado, a renda per capita chinesa poderia ser muito maior do que é atualmente, caso a corrupção chinesa estivesse há anos sob controle. Em contraste, o que se observa é a concentração dos ganhos nas mãos de poucos, além da destruição de diversas cadeias de produção. Ao final, com muita precisão, arremata que "se um país quer ser grande, ele precisa ter esse mal sob controle" (ANDRADE, 2015).

Como se vê, a corrupção não é exclusividade do Brasil, ainda que a intensidade com a qual ocorra em terra brasilis não encontre muitos paralelos na geografia global, pelo menos entre os países de grande envergadura econômica e populacional. Assim, é preciso reconhecer que o mal em questão faz parte, em alguma medida, da própria condição humana. Não obstante tal infeliz realidade, e embora a probabilidade de se eliminar por completo a corrupção seja remotíssima, a possibilidade de reduzi-la a níveis aceitáveis é real e viável. No caso do Brasil, forçoso reconhecer que o País convive com níveis inaceitáveis de corrupção, ou, talvez, mais evidentes, mormente devido à inauguração de instituições e procedimentos governamentais pseudodemocráticos e à facilidade e velocidade com que uma notícia pode ser divulgada. Malgrado o advento de instituições verdadeiramente independentes e autônomas - um Poder Judiciário Federal (BRASIL, 1966), um Ministério Público Federal efetivamente insubmisso (BRASIL, 1981) e uma Polícia Judiciária Federal forte e respeitável (BRASIL, 1965) -, é 
inegável que ainda não conseguimos eliminar o mal da corrupção (com todas as suas terríveis lógicas e consequências) do cotidiano nacional.

Tal quadro impõe uma conscientização e mudança de comportamento por parte da própria sociedade. Aliás, soa um tanto quanto evidente que não há corruptos sem corruptores. Mais do que isso, não há corrupção sem a presença desnecessária, massiva e invasiva do Estado, e de seus agentes públicos, na vida diária das pessoas. Conforme amplamente difundido pelo senso comum, criam-se "dificuldades" a fim de se obter "facilidades". Afinal, segundo o jargão próprio dos corruptos, "quem quer rir, precisa fazer rir".

\section{A DESMEDIDA INTERVENÇÃO ESTATAL NA VIDA DOS CIDADÃOS: A LÓGICA REATIVA DA CORRUPÇÃO}

Decerto que a corrupção encontra-se enraizada na sociedade brasileira, sendo perceptível desde as pequenas fraudes, tais como a sonegação de impostos, a consulta a livros e textos não autorizados em provas (a famosa "cola"), a aquisição de mercadorias pirateadas e muitas outras práticas que estão no nosso catálogo de condutas tidas como "socialmente normais". Mas não há como desconsiderar que a corrupção ostenta um viés de natureza específica e nitidamente reativa à exagerada e desnecessária intervenção estatal na vida dos cidadãos, os quais, em diversas ocasiões, deparam-se com verdadeiras "armadilhas" impostas pela burocracia estatal.

Em um País extremamente burocratizado e com uma "inflação legislativa" que efetivamente tortura e sufoca o cidadão, o descumprimento de normas jurídicas, muitas vezes por mero desconhecimento, passa a ser uma constante. A norma de Direito, portanto, não cumpre minimamente o papel para a qual restou concebida. Aliás, é importante que se ressalte que quanto mais burocratizado for um determinado país, mais corrupto ele será, ou no mínimo tenderá a sê-lo. Há, por assim dizer, uma relação direta entre burocracia e corrupção.

A questão, por exemplo, de se exigir complexas receitas médicas, de vários tipos e modelos, para a aquisição de praticamente todo e qualquer medicamento no Brasil, mesmo em se tratando de remédios simples e banais, fatalmente tende a 
descambar para a falsificação e o oportunismo. A lógica tem sido exatamente assim: quanto mais burocracia, mais corrupção.

Interessante anotar que o que se contesta - e se condena veementemente é justamente este excesso desarrazoado, cruel e muitas vezes desumano de ingerência estatal em todo e qualquer assunto, desde os mais comezinhos até os mais complexos, criando uma situação absurda e demagógica, induzindo a uma espécie de corrupção reativa, fenômeno que, em certa medida, e diferentemente de outras nações, traduz-se em uma autêntica característica da sociedade brasileira.

\section{CONSIDERAÇÕES FINAIS}

De qualquer modo, apesar de tal infeliz realidade nacional (e todas as respectivas lógicas), o Brasil, ainda que de forma tímida e extremamente pontual, tem evoluído no combate à corrupção. De fato, a partir do avanço da legislação penal e processual penal aplicável aos casos de malversação de recursos públicos, da introdução de novos instrumentos de controle por parte do Estado e, sobretudo, diante da solidez de algumas instituições nacionais (o Poder Judiciário Federal, o Ministério Público e a Polícia Federal, por exemplo), podemos afirmar que, em alguma medida (mesmo que setorialmente), quebramos o paradigma de que a lei não atinge os "poderosos", dado concreto que sinaliza que, mesmo caminhando a passos lentos, a sociedade brasileira não pode simplesmente desistir, e muito menos declinar deste grande desafio, que é o combate (contínuo e permanente) à corrupção.

Neste contexto, precisamos reconhecer que a maior mudança deve ocorrer em cada um de nós, de modo que o poder do exemplo individual continua sendo a melhor solução para sairmos deste cenário alarmante no qual o País se encontra mergulhado, provendo, enfim, a necessária dignidade a este povo que tanto almeja por transformação, notadamente através de uma menor ingerência estatal na vida social, motivo histórico e primaz da corrupção no mundo inteiro e, em particular, de forma mais enfática, no Brasil. 


\section{REFERÊNCIAS}

BRASIL. Lei Complementar no 40, de 14 de dezembro de 1981. Estabelece normas gerais a serem adotadas na organização do Ministério Público estadual. Brasília, DF: Presidência da República, 1981. Disponível em: http://www.planalto.gov.br/ccivil 03/leis/lcp/Lcp40.htm. Acesso: 27 jun. 2019.

BRASIL. Lei no 5.010, de 30 de maio de 1966. Organiza a Justiça Federal de primeira instância, e dá outras providências. Brasília, DF: Presidência da República, 1966. Disponível em: http://www.planalto.gov.br/ccivil 03/leis/L5010.htm. Acesso: 27 jun. 2019.

BRASIL. Lei $\mathbf{n}^{\circ} \mathbf{4 . 8 7 8}$, de 3 de dezembro de 1965. Dispõe sobre o regime jurídico peculiar dos funcionários policiais civis da União e do Distrito Federal. Brasília, DF: Presidência da República, 1965. Disponível em:

http://www.planalto.gov.br/ccivil 03/LEIS/L4878.htm. Acesso: 27 jun. 2019.

CREMONESE, Dejalma. A difícil construção da cidadania no Brasil, desenvolvimento e questão. Unijui, Ijuí, ano 5, n. 9, p. 59-84, jan./jun. 2007. Disponível em:

https://www.revistas.unijui.edu.br/index.php/desenvolvimentoemquestao/article/vie w/137/93. Acesso em: 30 out. 2017.

FEDERICI, Romulo F. A Europa está cercada e sendo invadida. Forças de Defesa, ano 5, n. 13, 2015.

ANDRADE, Cláudia. A corrupção será derrotada. Entrevistado: Robert Klitgaard. Revista Veja, ano 48, n. 19, ed. 2425, 13 de maio de 2015.

MONTEIRO, Ney Marino. Anos de Chumbo. Revista do Clube Naval, Rio de Janeiro, ano 125, n. 382, p. 30-31, abr./jun. 2017.

PAINS, Clarissa. Mau hábito que chegou com a corte. $\mathbf{0}$ Globo, p. 25, Rio de Janeiro, 5 set. 2015.

SOUZA, Ludmilla. Índice de Percepção da Corrupção no Brasil tem queda e país fica pior no ranking. Agência Brasil, São Paulo, 21 fev. 2018. 